\title{
Experimental cerebral schistosomiasis japonica in primates
}

\author{
JOHN A. JANE, KENNETH S. WARREN, AND STANLEY VAN DEN NOORT \\ From the Department of Neurosurgery, University of Virginia, School of Medicine, Charlottesville, Virginia \\ 22901, and the Department of Preventive Medicine and Medicine, Division of Neurology, Case Western \\ Reserve University, School of Medicine and University Hospitals, Cleveland, Ohio 44106, U.S.A.
}

SUMMARY Aspects of the pathogenesis of cerebral schistosomiasis have been elucidated. Arterial embolization alone, by either worms or eggs, does not appear to be likely as a major cause of the disease. When large numbers of eggs enter the brain, sensitization may play a role in the occurrence of neurological signs. These studies support but do not prove the theory that worms in the cerebral veins lay eggs that then cause the disease.

Schistosomiasis japonica is a parasitic worm disease of great potential severity which involves more than $30,000,000$ people in the Far East. While the most common signs and symptoms are related to an acute febrile illness known as Katayama fever and chronic involvement of the intestine and liver, it has been estimated that between 2 and $4 \%$ of all patients with this disease may manifest symptoms of cerebral involvement (Kane and Most, 1948; Ariizumi, 1963; Reyes, Yogore, and Pardo, 1964). The specific cause of the neurological complications of schistosomiasis remains unknown, although it is generally believed that the eggs of the parasite are the major aetiological factor. The route by which the eggs enter the brain is also unknown. It has been speculated that either eggs produced by worm pairs in their usual sites embolize to the brain or that worms present in cerebral vessels are producing eggs in situ. In view of the clinical importance of cerebral schistosomiasis and the lack of knowledge concerning its aetiology, it is interesting to observe that no studies of cerebral schistosomiasis have ever been performed in experimental animals (Warren and Newill, 1967). There has been only an incidental observation of Fujinami as reported by Schmidzu (1935) of worms in the brain of hyperinfected experimental animals. In the present investigation, several possible aetiologies of cerebral schistosomiasis japonica have been examined in the African green monkey, Cercopithecus aethiops.

\section{MATERIALS AND METHODS}

Twenty monkeys (Cercopithecus aethiops) of both sexes weighing $2 \cdot 1$ to $4.6 \mathrm{~kg}$ were used in the present study. They were divided into the following five groups:

GROUP 1 Cranial exposure to cercariae Two monkeyss were anaesthetized with Sernylan $(10 \mathrm{mg} / \mathrm{kg})$, their headsक and faces shaved, and the skin moistened with saline $ᄋ$ 을 Using a bacteriologist's loop, 150 cercariae of a Japanese⿻ strain of Schistosoma japonicum were placed in smallo groups on either side of the bridge of the nose in the upper inner quadrant of both orbits, along the sagittap sinus and the occiput of each animal.

GROUP 2 Intracarotid injection of worm pairs Two monkeys were anaesthetized (Sernylan) and a small polyethylene catheter was threaded into the left common carotid artery. Seven actively motile worm pairs were obtained by the perfusion method of Duvall and DeWitt (1967) from female Swiss albino mice infected for eight weeks with $S$. japonicum. The worms were suspended in sterile saline and injected into the catheter within 20 minutes of the perfusion procedure. During this procedure, and all those below involving injection of material into the carotid artery, electroencephalograms were recorded from six surface electrodes with a standard clinical Grass electroencephalograph. The catheter was removed and the incision was closed with fine arterial silk maintaining the continuity of the vessel. These monkeys and all of those in the following experiments were treated with $125 \mathrm{mg}$ ampicillin (two doses intramuscularly) on the day of the operative procedure.

GROUP 3 Jugular vein and sagittal sinus placement of worm pairs Six monkeys premedicated with Sernylan were placed under general endotracheal anaesthesia with halothane. The left jugular vein was ligated and from three to 12 worm pairs, obtained as described above, were injected into the vein above the ligation. Thirtyfive days later two of the six monkeys had three worm 
pairs placed into a small segment of the anterior sagittal sinus isolated by ligatures at open craniotomy.

GROUP 4 Intracarotid injection of schistosome eggs $S$. japonicum eggs were isolated by the method of Browne and Thomas (1963) from the livers and intestines of mice infected for eight weeks. These were injected into the left carotid artery of eight monkeys twice, two weeks apart (Table). The eggs were ellipsoidal in shape and their mean width, as measured by a Cooke Image Splitting Eyepiece, was $60 \mu$.

GROUP 5 Intracarotid injection of plastic beads In the same manner as in group 2 and 4, divinylbenzene copolymer beads (Bio Rad) were injected into the carotid artery of two monkeys on two occasions separated by two weeks. On the first occasion one monkey received 84,000 beads and the other 60,000 beads with a mean diameter of $45 \mu$ measured as described above. For the second injection both monkeys received 50,000 beads with a mean diameter of $57 \mu$.

Approximately 12 weeks after the procedure described above, all the animals remaining alive had electroencephalograms and then were killed by the rapid injection of $10 \mathrm{ml}$ Diabutol $(50 \mathrm{mg} / \mathrm{ml})$. In the case of the animals which had living worm pairs placed in the venous circulation, cranial venous drainage was occluded by a cervical tourniquet within five seconds after loss of consciousness in order to maintain intracranial worm pairs in situ. The brains in all cases were removed and placed in formalin. They were sectioned grossly and appropriate samples of tissue for microscope sections were obtained. At the time of death, portions of the liver and intestine of each animal were pressed between two glass plates, except for the monkeys which had been exposed to cercariae, and no sign of prior infection with schistosomes was observed.

\section{RESULTS}

The two monkeys exposed cranially to $S$. japanicum cercariae showed no cerebral symptomatology over a period of 86 days after exposure. At the termination of the experiment their electroencephalograms were normal.Post-mortem examination revealed that both monkeys were infected with $S$. japonicum and that they had the usual intestinal and liver involvement.

Neither of the two monkeys which received seven worm pairs into the carotid artery showed any immediate neurological manifestations, or EEG changes, and both recovered completely from anaesthesia. They both appeared completely well two days after the procedure, but at four days one of them was anorexic. On the next day the animal was found in a comatose state and shortly thereafter died. At post-mortem examination left uncal herniation was observed. In addition, a large haemorrhage extended from the level of the lateral geniculate in the posterior temporal lobe to the external capsule and involved the putamen. No parasitic elements were observed on microscopic examination of sections taken from the haemorrhagic area. The other monkey had no neurological signs or symptoms and when killed 34 days after worm injection the brain was grossly normal.

Of the six animals in which worm pairs were implanted into the jugular vein or the sagittal sinus, none had any neurological signs, symptoms, or electroencephalographic changes over a period of 90 days nor were any striking changes noted in the brains at necropsy.

Of the eight monkeys injected for the first time with eggs $(4: 50,000 ; 2: 10,000 ; 1: 1,000 ; 1: 100)$ six showed no neurological signs or symptoms whatsoever but two animals failed to regain consciousness; one of these received 50,000 eggs, the other 10,000 eggs (Table). On post-mortem examination the former animal had marked congestion and haemorrhage over the left hemisphere and ecchymoses in the Sylvian fissure (Fig. 1). In spite of these changes,

TABLE

EFFECTS ON Cercopithecus aethiops OF PRIMARY AND SECONDARY INTRACAROTID INJECTIONS OF Schistosoma japonicum EGGS

\begin{tabular}{cccccc}
\hline Animal & $\begin{array}{c}\text { First } \\
\text { injection }\end{array}$ & Result & $\begin{array}{c}\text { Second } \\
\text { injection }\end{array}$ & Result \\
pathology
\end{tabular}




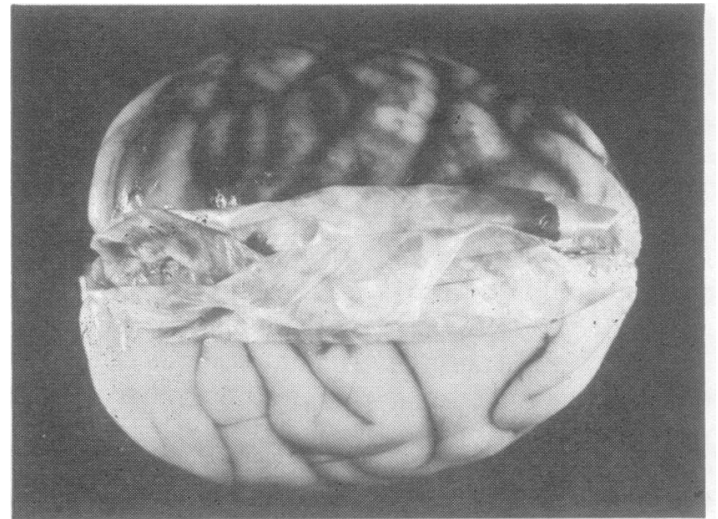

FIG. 1. Dorsal surface of brain with dura reflected showing subarachnoid haemorrhage.

remarkably little was observed on cross-section (Fig. 2). The brain of the latter monkey appeared normal. In neither animal were any parasitic elements seen on microscopic examination.

On the second injection of eggs, five of the six animals either had severe neurological signs or died. Striking neurological signs, including decerebrate rigidity and marked right hemiparesis accompanied by hemianopsia, appeared immediately after injection in the four animals injected with 50,000 or 10,000 eggs (Table). The monkeys which received

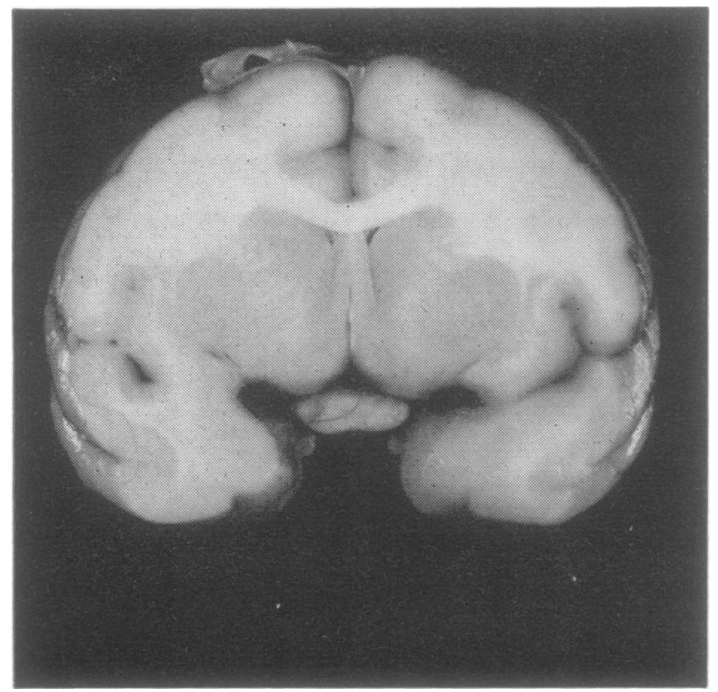

FIG. 2. Cut surface of brain showing poor grey white differentiation and subarachnoid haemorrhage but very little oedema.

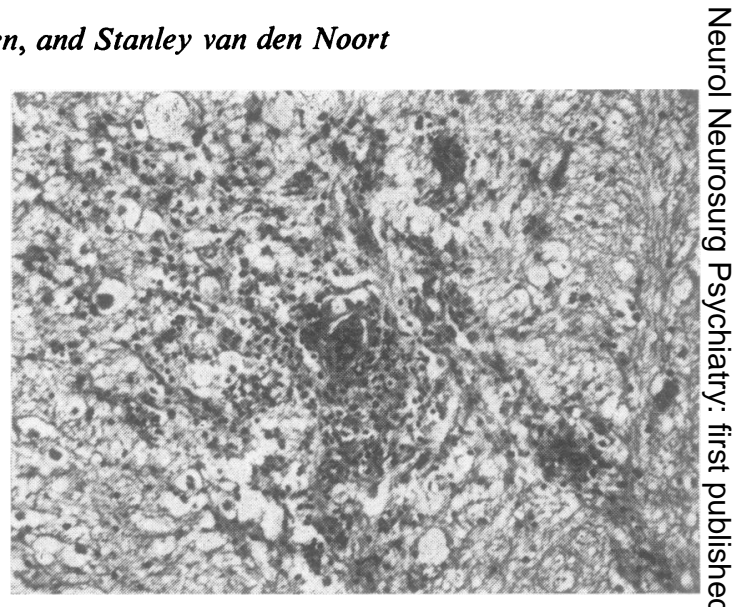

FIG. 3. Granulomatous reaction around a schistome egg.

1,000 and 100 eggs showed no immediate changes $\overrightarrow{\vec{\omega}}$ and by 24 hours both had recovered and were in excellent condition. The former animal, however,

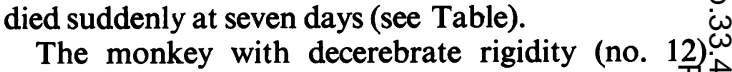
died at 24 hours and haemorrhage was observed over the left frontal lobe and at the base. Micro scopic examination of tissue taken from the brail of this monkey revealed an egg in the cerebral sub-stance with a marked granulomatous reaction around it (Fig. 3) and a group of eggs in a blogto vessel in the midst of an organizing thrombus (Fes. 4). In one of the animals which developed hen $-\vec{\theta}$ paresis on second injection (no. 13) an egg wass found with no reaction around it (Fig. 5). The three monkeys with right hemiparesis recovered over the next 24 hours, but were killed five days later.

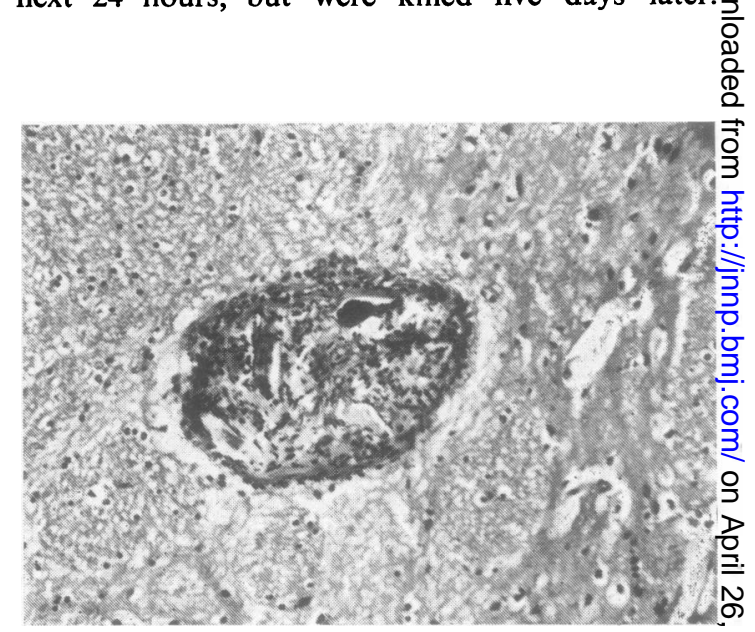

FIG. 4. Organizing thrombus with schistosome eggs but very little perivascular reaction. 


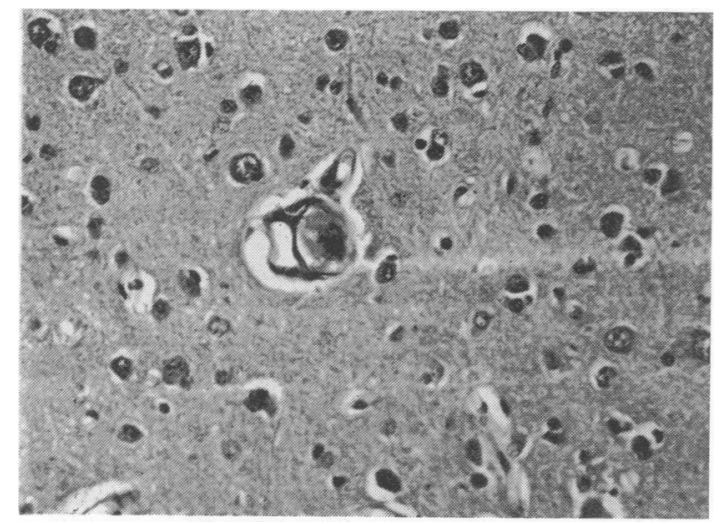

FIG. 5. Schistosome egg in a small vessel with no reaction.

Only one of these monkeys (no. 14) showed any gross cerebral changes-haemorrhage in the pia over the left hemisphere.

None of the animals receiving the two injections of glass beads showed any abnormal signs or symptoms.

\section{DISCUSSION}

- Cerebral schistosomiasis japonica has been estimated to occur among 2 to $4 \%$ of the $30,000,000$ Asians infected with Schistosoma japonicum (Kane and Most, 1948; Ariizumi, 1963; Reyes et al., 1964). The way in which the central nervous system is involved by this parasite of the gastrointestinal tract is unknown, but there are several aspects to the disease picture which are of aetiological significance. Although overt cerebral involvement may occur at any time during the course of this prolonged chronic infection, it may appear as early as four weeks after exposure to the infective forms of the parasite (Kane and Most, 1948). The clinical disease may be manifest by diffuse or focal signs of deficit or increased excitability, but commonly there is a focal deficit (Kane and Most, 1948; Ariizumi, 1963; Reyes et al., 1964). Most of the cerebral lesions found at surgery in patients with localizing signs have been circumscribed masses of eggs which are usually located in the venules and not the arterioles (Kane and Most, - 1948; Ariizumi, 1963, Reyes et al., 1964). Finally, it should be pointed out that cerebral schistosomiasis does not merely denote the presence of eggs scattered about the brain, since this has been demon'strated at necropsy in many patients infected with $S$. japonicum who do not have signs or symptoms. Moreover, cerebral signs are extremely rare in patients with schistosomiasis mansoni and haema- tobia yet eggs have been found in the brains of more than $50 \%$ of such patients by digestion procedures (Gelfand, 1950). Histological examination of brain sections also revealed $S$. mansoni eggs in patients with no neurological signs and symptoms (Aleman, 1966).

When approached in the above manner, the most likely explanation for most cases of cerebral schistosomiasis is the presence of egg-producing worm pairs in the venous circulation of the brain (Greenfield and Pritchard, 1937). Nevertheless, Kane and Most (1948) noted that most investigations supported the theory of indirect (or embolic) deposition of eggs, either through arteriovenous anastomoses or from worms in the pulmonary venous circulation. In these conditions, it is also possible that the worms themselves may act as emboli. If adult worms are in the cerebral veins, they may get there at three different stages of their development: as cercariae when they penetrate the skin, as schistosomulae when they migrate from the lungs, or as adult worms migrating from the mesenteric veins.

All of the above aetiological possibilities were considered in the experimental plan of the present investigation. Thus cercariae were applied to the cranium, living worm pairs were injected into the carotid artery or placed in the venous circulation of the brain, and schistosome eggs or plastic beads of similar size were injected into the carotid artery. Consultation with several investigators in the field of schistosomiasis led to the suggestion that exposure of the cranial area to cercariae might lead to passage of schistosomulae through the emissary veins and into the cerebral vessels where they would develop into worms. Although no cerebral signs or symptoms were observed in our animals treated in this manner, only two monkeys were studied. Nevertheless it was not unpredictable that at necropsy the worms, which usually proceed from the site of infection to the lungs and then to the mesenteric veins, were found in their usual final location. Adult worms (about 0.6 by $2.5 \mathrm{~cm}$ ) injected into the cerebral arteries did not produce the expected result of neurological signs. One of the two animals treated in this drastic manner had no changes whatsoever, while the effect on the other animal was delayed for approximately one week and was perhaps related to the delayed onset of an inflammatory reaction around the dead worms (Warren, Domingo, and Cowen, 1967); it is unlikely that conditions similar to those in these experiments occur in the natural course of infection. The response to the second injection of eggs did not appear to be related to granuloma formation as in some cases there were profound inflammatory reactions around the eggs (Fig. 3), but in others there were none 
(Fig. 5). Finally, the haemorrhagic lesions observed in the primates at necropsy bear no relation to the surgical or post-mortem findings in man.

\section{REFERENCES}

Alemán, G. C. (1966). Localizacion ectopica aparentemente asintomatica de huevos de Schistosoma mansoni en el encefalo. Reporte de cuatro casos. Arch. Hosp. Vargas, $8,71-84$.

Ariizumi, M. (1963). Cerebral schistosomiasis japonica: Report of one operated case and fifty clinical cases. Amer.J. trop. Med. Hyg., 12, 40-45.

Browne, H. G., and Thomas, J. E. (1963). A method for isolating pure, viable schistosome eggs from host tissues. J. Parasitol., 49, 371-374.

Duvall, R. H., and DeWitt, W. B. (1967). An improved perfusion technique for recovering adult schistosomes from laboratory animals. Amer. J.trop. Med. Hyg., 16, 483-486.

Gelfand, M. (1950). Schistosomiasis in South Central Africa. Juta: Cape Town.
Greenfield, J. G., and Pritchard, B. (1937). Cerebral infectio $\bar{\nabla}$ with Schistosoma Japonicum. Brain, 60, 361-372.

Kane, C. A., and Most, H. (1948). Schistosomiasis of the central nervous system; experiences in World War and review of literature. Arch. Neurol. Psychiat., 59 141-183.

Reyes, V. A., Yogore, M. G., and Pardo, L. P. (1964) Studies on cerebral schistosomiasis. J. Philipp. med. Ass 40, 87-100.

Schmidzu, K. (1935). Ein Operationsfall von Schistosomiosi cerebri. Langenbecks Arch. klin. Chir., 182, 401-407.

Smithers, S. R., Terry, R. J., and Hockley, D. J. (1969) Host antigens in schistosomiasis. Proc. roy. Soc. $B$ 方 171, 483-494.

Warren, K. S. (1970). Intestinal obstruction in murine schistosomiasis japonica. Gastroenterol. (In press.)

Warren, K. S., Domingo, E. O., and Cowan, R. B. T. (1967) Granuloma formation around schistosome eggs as manifestation of delayed hypersensitivity. Amer. Pि Path., 51, 735-756.

Warren, K. S. and Newill, V. A. (1967) Schistosomiasis: A Bibliography of the World's Literature from 1852 to 1962. The Press of the Western Reserve University: Cleveland, Ohio. 